\title{
KAJIAN MANFAAT DAN KELAYAKAN EKONOMI BUDI DAYA SUREN PADA MASYARAKAT DESA SIPOLHA HORISON, KABUPATEN SIMALUNGUN, PROVINSI SUMATERA UTARA (Study of the Benefits and Economic Feasibility of Suren Cultivation in Sipolha Horison Village, Simalungun Regency, North Sumatera Province)
}

Siti Latifah*, Heriyadi Mukti Sima, dan/and Agus Purwoko

Program Studi Kehutanan, Fakultas Kehutanan, Universitas Sumatera Utara, 20155 Tlp : (061) 8220605; Fax : (061) 8201920

E-mail : siti latifah164@yahoo.co.id*; simaheri7@gmail.com; aguspurwokousu@yahoo.com

Tanggal diterima: 9 Juni 2020; Tanggal disetujui: 19 Oktober 2020; Tanggal direvisi: 19 Oktober 2020

\begin{abstract}
Forests play an important role in the livelihoods of local people in most developing countries. Local people depend on forest resources for various products such as building materials, medicines, and food. This study examined the benefits and economic feasibility of suren (Toona sureni) cultivation as a forest plant species that is widely used by local people for various needs. Interviews were conducted with selected respondents of forest communities in Sipolha Horison Village, Pematang Sidamanik District, Simalungun Regency, North Sumatra Province by purposive sampling method from May to June 2018. The analysis of the benefits of suren wascarried out in a qualitative descriptive method. Simultaneously, the economic assessment was done by using NPV (Net Present Value) to determine the feasibility of suren cultivation. The results showed that the local people used suren trees as land boundaries and shade. The plants'stem were used for house walls, house frames, boats and ships, while the leaves were commonly used for fresh vegetables, medicines and natural insecticide. The NPV value obtained with an interest rate of $17.5 \%$ was 29,153,089 IDR/ha/cycle, which indicates that the cultivation of suren is feasible to develop.
\end{abstract}

Keywords: Toona sureni, Net Present Value, benefits, economy, feasibility

\begin{abstract}
ABSTRAK
Hutan berperan penting dalam mata pencaharian masyarakat lokal di sebagian besar negara berkembang. Masyarakat lokal bergantung pada sumber daya hutan untuk berbagai produk seperti bahan bangunan, obat-obatan, dan makanan. Studi ini mengkaji manfaat dan kelayakan budi daya ekonomi suren (Toona sureni) sebagai salah satu spesies tumbuhan hutan yang banyak dimanfaatkan masyarakat setempat untuk berbagai kebutuhan. Wawancara dilakukan secara purposive sampling selama bulan Mei-Juni 2018 terhadap masyarakat sekitar hutan di Desa Sipolha Horison Kecamatan Pematang Sidamanik Kabupaten Simalungun, Provinsi Sumatera Utara. Kajian manfaat suren dilakukan secara deskriptif kualitatif, sedangkan penilaian ekonominya menggunakan NPV (Net Present Value) untuk mengetahui kelayakan pengusahaan suren. Hasil penelitian menunjukkan bahwa masyarakat memanfaatkan pohon suren sebagai pembatas lahan dan naungan. Batang tanamannya digunakan untuk dinding rumah, kusen, perahu dan kapal, sedangkan daunnya digunakan untuk lalapan makan, obat-obatan dan insektisida alami. Nilai NPV yang
\end{abstract}


diperoleh dengan tingkat suku bunga 17,5\% adalah $\mathrm{Rp} 29.153 .089$ ha/daur, yang menunjukkan bahwa budi daya tanaman suren layak dikembangkan.

Kata kunci : Toona sureni, Net Present Value, manfaat, ekonomi, kelayakan

\section{PENDAHULUAN}

Keadaan masyarakat sekitar hutan pada umumnya miskin dan berpendidikan rendah. Kondisi tersebut seringkali membuat mereka merambah kawasan hutan, karena terbatasnya lahan garapan dan terbatasnya pilihan sumber penghidupan (Dewi, 2018). Meningkatnya pertambahan penduduk saat ini yang menyebabkan timbulnya tekanan yang serius terhadap sumber daya hutan, hal ini menyebabkan perlunya penyempurnaan pengelolaan sumber daya alam melalui penilaian akurat terhadap nilai ekonomi sumber daya alam (Pandey, Tripathi, \& Kumar, 2016).

Sebagai sumber daya alam yang terbarukan, hutan memiliki berbagai manfaat penting bagi keberlangsungan mahluk hidup. Hutan harus dikelola dengan baik, agar dapat memberikan manfaat optimal bagi masyarakat, pengelola hutan dan stakeholder lain serta lingkungan sekitarnya (Herawati \& Santoso, 2011). Pengelolaan hutan berbasis masyarakat di beberapa negara telah bergeser dari pengelolaan secara subsisten menuju ke pengelolaan hutan secara komersial dalam berbagai model bisnis. Pengelolaan hutan komersial berbasis masyarakat merupakan salah satu kebijakan prioritas pemerintah Indonesia (Irawanti, Suka, \& Ekawati, 2012)

Berkaitan dengan hal tersebut, pemerintah mendorong pembangunan industri berbasis hasil hutan, termasuk di tingkat masyarakat untuk meningkatkan kontribusi ekonomi sektor kehutanan secara nasional (Aji, Suryanto, Yulianti, Wirati, Abdurrahim, \& Miranda, 2013). Pemerintah mengalokasikan lahan seluas 12,7 juta ha untuk program perhutanan sosial khususnya lima skema pada kawasan hutan selama periode 2015-2019 (Suharti, Ginoga, Murniati, Octavia, \& Windyoningrum,
2017). Hingga tahun 2019 ditargetkan 5.000 kelompok usaha sosial dan kemitraan akan dikembangkan melalui program perhutanan sosial. Kelompok-kelompok inilah yang diharapkan mewadahi masyarakat miskin sekitar hutan dan dapat berkembang serta pada akhirnya meningkat kesejahteraannya (Suharti et al., 2017).

Salah satu bentuk usaha perhutanan sosial adalah pengembangan industri perkayuan berbasis masyarakat. Untuk menjamin terpenuhinya kebutuhan industri perkayuan dibutuhkan jenis tanaman yang cepat tumbuh dan memiliki nilai jual yang tinggi yang salah satunya adalah suren (Toona sureni (Juss.) M. Roem.) sebagai jenis pohon serbaguna (JPSG). Semua bagian tanaman suren dapat dimanfaatkan. Kayu suren banyak digunakan untuk keperluan pertukangan, akar dan kulitnya dapat dimanfaatkan untuk obat diare, sementara daun mudanya dimanfaatkan sebagai sayuran dan dapat diproses menjadi insektisida alami (Lestari, \& Darwiati, 2014).

Pohon suren sangat cocok tumbuh di ketinggian 350-2.500 m dpl, cepat tumbuh dan dapat hidup di lahan yang memiliki $\mathrm{pH}$ rendah. Kayunya memiliki sifat rekat yang sangat baik dan kulitnya sebagai nanofiller berfungsi untuk memperbaiki kualitas perekatan (Pandit, Nandika, \& Darmawan, 2011).

Kegiatan agroforestri dengan menanam pohon suren dan tanaman kakao pada masyarakat Desa Mekar Sari Raya Kabupaten Simalungun diharapkan dapat meningkatkan pendapatan petani, mengembangkan kegiatan ekonomi pedesaan, dan mewujudkan sistem ketahanan pangan (Latifah, Purwoko, Hartini, Sadeli, \& Tambal, 2019). Tanaman suren cocok ditanam pada lahan kritis karena kemampuannya dalam 
menyesuaikan dengan karakter fisik tanah marginal.

Pertumbuhan tanaman suren akan optimal jika ditanam sebagai tanaman sela diantara tanaman pertanian atau sebagai tanaman pagar di daerah Sumatera Utara. Pertumbuhan riap diameternya rata-rata pertahun mencapai 3-4 cm/tahun apabila ditanam pada tapak yang sesuai. Umur panen diatas 10 tahun pada diameter 30-40 $\mathrm{cm}$. Harga kayu suren berupa tegakan berdiri dengan diameter $30-40 \mathrm{~cm}$ antara Rp 1-2 juta/ $\mathrm{m}^{3}$, sedangkan kayu olahan (kayu gergajian) harganya bisa mencapai $\mathrm{Rp}$ 4-6 juta/ $\mathrm{m}^{3}$ (Asmaliyah, 2014).

Terlepas dari berbagai potensi manfaat dan harga suren, masih terdapat beberapa tantangan dalam pengembangannya, yaitu belum membudayanya usaha pelestarian tanaman suren serta kurangnya bentuk pengusahaan dan pengelolaan hutan rakyat suren. Kondisi ini mengakibatkan pengusahaan suren dari aspek ekonomi belum optimal. Penelitian ini bertujuan untuk mengkaji lebih dalam pemanfaatan suren dan kelayakan ekonomi budi daya suren dengan menggunakan kriteria kelayakan Net Present Value (NPV) pada masyarakat di Desa Sipolha Horison, Kecamatan Pematang Sidamanik, Kabupaten Simalungun, Provinsi Sumatera Utara.

\section{METODOLOGI}

\section{A. Lokasi Penelitian dan Waktu Penelitian}

Penelitian dilaksanakan di Desa Sipolha Horison, Kecamatan Pematang Sidamanik, Kabupaten Simalungun, Provinsi Sumatera Utara. Penelitian dilakukan pada bulan April 2018 sampai dengan Juni 2018. Secara umum hutan di Kawasan Kelurahan Sipolha Horison berada pada ketinggian 400-600 m di atas permukaan laut dan memiliki karakterisitik topografi berombak dengan kemiringan lahan $10-45^{\circ}$.
Batas-batas yang mengelilingi Desa Sipolha Horison sebagai berikut :
a. Sebelah Utara : Jorlang Huluan (Lahan Kehutanan)
b. Sebelah Timur
Kecamatan Girsang Sipangan Bolon
c. Sebelah Selatan : Danau Toba
d. Sebelah Barat

Desa Tambun
Raya, Kecamatan
Pematang
Sidamanik

\section{B. Metode}

\section{Pengumpulan data}

Metode pengambilan contoh yang digunakan adalah purposive sampling, yang merupakan metode pengambilan contoh dengan disengaja berdasarkan tujuan penelitian, yaitu masyarakat desa yang memanfaatkan tanaman suren. Apabila subjeknya kurang dari 100 orang lebih baik diambil semua, sehingga penelitiannya merupakan penelitian populasi. Jika jumlahnya lebih besar dari 100 orang, maka diambil antara $10-15 \%$ atau $20-25 \%$ (Arikunto, 2006). Berdasarkan angka yang diperoleh, diketahui bahwa jumlah pengelola tanaman suren di Desa Sipolha sebesar $356 \mathrm{KK}$, sehingga sample yang diambil adalah $10 \%$ x $356=35,6 \mathrm{KK}$ dengan pembulatan menjadi $36 \mathrm{KK}$.

Teknik pengumpulan data dalam penelitian dilakukan dengan (i) wawancara terstruktur dengan menggunakan pertanyaan (kuisioner) yang telah disiapkan peneliti (Gambar 1); (ii) observasi lapangan, yaitu suatu cara untuk memperoleh data melalui kegiatan pengamatan langsung terhadap objek penelitian untuk memperoleh keterangan yang relevan dengan objek penelitian. Seluruh peneliti turut serta dalam rangkaian kegiatan pengumpulan data di lapangan dengan durasi waktu yang berbeda. Data yang dikumpulkan, adalah (i) karakteristik responden, meliputi umur, jenis kelamin, mata pencaharian, pendidikan; (ii) karekterisktik tanaman suren meliputi bagian tanaman yang dimanfaatkan, tujuan 
pemanfaatan, jumlah, waktu dan pengambilan, nilai biaya dan keuntungan yang diperoleh dari pemanfaatan suren.

\section{Pengolahan dan analisis data}

Proses pengolahan dan analisis data menggunakan program spread sheet dan SPSS. Analisis kajian manfaat suren dilakukan secara deskriptif kualitatif, yaitu dengan wawancara kepada responden untuk mendapatkan informasi bagian tanaman dan tujuan pemanfaatan tanaman suren. Sedangkan analisis penilaian ekonomi menggunakan NPV (Net Present Value) untuk mengetahui kelayakan dari sistem usaha tani (Latifah, Afifuddin, \& Widya, 2018).

$$
\mathrm{NPV}=\sum_{t=1}^{n} \frac{B t-C t}{(1+1) t}
$$

Keterangan :

$\mathrm{Bt}$ : Penerimaan kotor pada tahun $\mathrm{t}$

$\mathrm{Ct}$ : Biaya Kotor usaha tani pada tahun $\mathrm{t}$

$\mathrm{n}$ : Umur ekonomis

i : Discount rate

$\mathrm{t}$ : Periode waktu
Indikator :

NPV $=0$ Maka nilai usaha sebesar tingkat suku bunga yang berlaku di bank. NPV > 0 Maka usaha menguntungkan. NPV < 0 Maka usaha rugi.

\section{HASIL DAN PEMBAHASAN}

\section{A. Hasil}

\section{Karakteristik masyarakat desa sekitar hutan}

Jumlah total penduduk di Desa Sipolha Horison sebanyak 1.180 jiwa, dengan jumlah kepala keluarga 356 KK. Perbandingan jumlah penduduk wanita dan pria di Kelurahan Sipolha Horison adalah 585 jiwa jumlah penduduk pria dan 595 jiwa jumlah penduduk wanita. Mayoritas penduduk bermata pencaharian utama sebagai petani, hanya sebagian kecil yang bekerja sebagai pedagang dan PNS. Sumber penghasilan utama berasal dari kegiatan budi daya padi dan kopi. Selain itu, petani juga menanam berbagai jenis pohon serbaguna (JPSG), seperti kemiri, cengkeh, mangga, durian, dan tanaman semusim seperti sayuran, jagung dan cabai. Tabel 1. menunjukkan bahwa umur responden petani suren terbanyak berada pada kelompok umur antara 41-49 tahun, sedangkan jumlah responden yang paling sedikit berada pada kelompok 70-79 tahun.



a. Hutan tanaman suren sebagai obyek penelitian (Suren plantation forest as study location) b. Wawancara dengan responden (Interview with respondents)

Gambar ( Figure ) 1. Kegiatan pengumpulan data (Data collection activities) 
Tabel (Table) 1. Klasifikasi responden menurut umur (Classification of Respondents by Age)

\begin{tabular}{cccc}
\hline No & $\begin{array}{c}\text { Kelas umur (tahun) } \\
\text { (Age class-year) }\end{array}$ & $\begin{array}{c}\text { Jumlah orang } \\
\text { ( Number of } \\
\text { people })\end{array}$ & $\begin{array}{c}\text { Persentase } \\
\text { (Percentage) }(\%)\end{array}$ \\
\hline 1 & $35-40$ & 11 & 30,55 \\
2 & $41-49$ & 13 & 36,11 \\
3 & $50-59$ & 9 & 25,00 \\
4 & $60-69$ & 2 & 5,55 \\
5 & $70-79$ & 1 & 2,77 \\
\hline
\end{tabular}

Sumber (Source) : Data primer diolah, 2010 (Primary data processed, 2010)

Tabel (Table) 2. Tingkat pendidikan responden (Education level of the respondent)

\begin{tabular}{clcc}
\hline No & $\begin{array}{c}\text { Tingkat pendidikan } \\
(\text { Education level) }\end{array}$ & $\begin{array}{c}\text { Jumlah orang } \\
\text { (Number of } \\
\text { people) }\end{array}$ & $(\%)$ \\
\hline 1 & SD (Elementary school) & 4 & 11,11 \\
2 & SMP (Junior high school) & 12 & 33,33 \\
3 & SMA (Senior high school) & 17 & 47,22 \\
4 & Perguruan Tinggi (College) & 3 & 8,33 \\
\hline
\end{tabular}

Sumber (Source): Data primer diolah, 2018 (Primary data processed, 2018)

Tabel (Table) 3. Luas lahan (Land area)

\begin{tabular}{lccc} 
No & $\begin{array}{c}\text { Luas lahan } \\
\text { Land area }) \\
\text { (ha) }\end{array}$ & $\begin{array}{c}\text { Jumlah orang } \\
\text { (Number of people) }\end{array}$ & $\begin{array}{c}\text { Persentasi } \\
\text { (Percentage) }(\%)\end{array}$ \\
\hline 1. & $0,24-0,52$ & 23 & 63,88 \\
2. & $0,60-0,79$ & 7 & 19,44 \\
3. & $1,04-1,45$ & 6 & 16,66 \\
\hline
\end{tabular}

Sumber (Sources): Data primer diolah, 2018 (Primary data processed, 2018)

Tingkat pendidikan responden relatif tinggi, yaitu SMP, SMA dan perguruan tinggi, masing-masing dengan proporsi lebih dari $33 \%, 47 \%$ dan $8 \%$. Sementara itu responden dengan tingkat pendidikan dasar (SD) relatif sangat sedikit (11\%). Hal ini menunjukkan bahwa sebagian besar penduduk Desa Sipolha Horison berpendidikan cukup tinggi (menengah ke atas). Untuk ukuran desa pada kondisi tersebut, tingkat pendidikan SMA dan perguruan tinggi tergolong cukup tinggi, mengingat masih banyak penduduk di daerah pedesaan yang hanya berpendidikan SD atau bahkan buta huruf. Usaha tani suren yang selama ini dilakukan secara turun temurun, sehingga petani hanya mengandalkan kemampuan dan pengalaman yang dimiliki.

Tabel 3. menunjukkan bahwa lahan yang dimiliki responden di Desa Sipolha Horisan umumnya relatif sempit yaitu sekitar 0,24-0,52 ha. Hanya $16 \%$ responden di lokasi penelitian yang memiliki luas lahan garapan $>1$ ha.

\section{Pemanfaatan suren oleh masyarakat}

Kayu teras suren (Toona sureni) berwarna merah pucat sampai merah dan lama kelamaan berubah menjadi merah kecoklatan, mudah dibedakan dengan gubalnya berwarna putih keabu-abuan. Arah seratnya lurus sampai berpadu dan teksturnya agak kasar. Pola penyebaran sel 
pembuluh tata lingkar menyebabkan kayu suren menampilkan corak dekoratif unik. Pori sebagian soliter dan bergabung radial sampai miring terdiri 2-3 pori, berisi endapan berwarna merah. Parenkim aksial tersusun atas parenkim selubung sampai bentuk pita marginal. Parenkim jari-jarinya agak sempit sampai lebar, frekuensinya, agak jarang dan tergolong berukuran pendek. Berat jenis kayu suren 0,37 (0,27$0,67)$, kelas kekuatan kayu suren di tingkat IV dan Kelas Awet kayu suren di tingkat IV-V (Pandit et al., 2011).

Seluruh responden memanfaatkan bagian batang pohon suren untuk dinding rumah, kusen dan bahan pembuatan kapal atau sampan. (Gambar 2.). Pada saat observasi di lapangan, didapatkan bahwa di lahan petani, kayu suren dimanfaatkan sebagai pembatas lahan dan naungan tanaman kopi (Gambar 3a.). Daun suren yang masih muda dimanfaatkan masyarakat untuk lalapan makan, insektisida alami dan obat-obatan (Gambar 3b.).

\section{Kelayakan ekonomi budi daya tanaman suren}

Masyarakat melakukan pola tanam sistem agroforestri pada asing - masing lahan garapan dengan mengkombinasikan tanaman tahunan, seperti alpukat, mangga, kemiri dan tanaman semusim seperti cabe, jahe dan jagung (Tabel 4.).

Hasil penelitian menunjukkan bahwa nilai Net Present Value (NPV) terbesar pada Discount factor (df) $17,5 \%$ dengan nilai Rp 2.451.064/ha/daur yang terkecil nilai NPV sebesar Rp 194.860/ha/daur (daur tebang 15 tahun) dan nilai total NPV sebesar Rp 29.153.089 (Lampiran 1.).

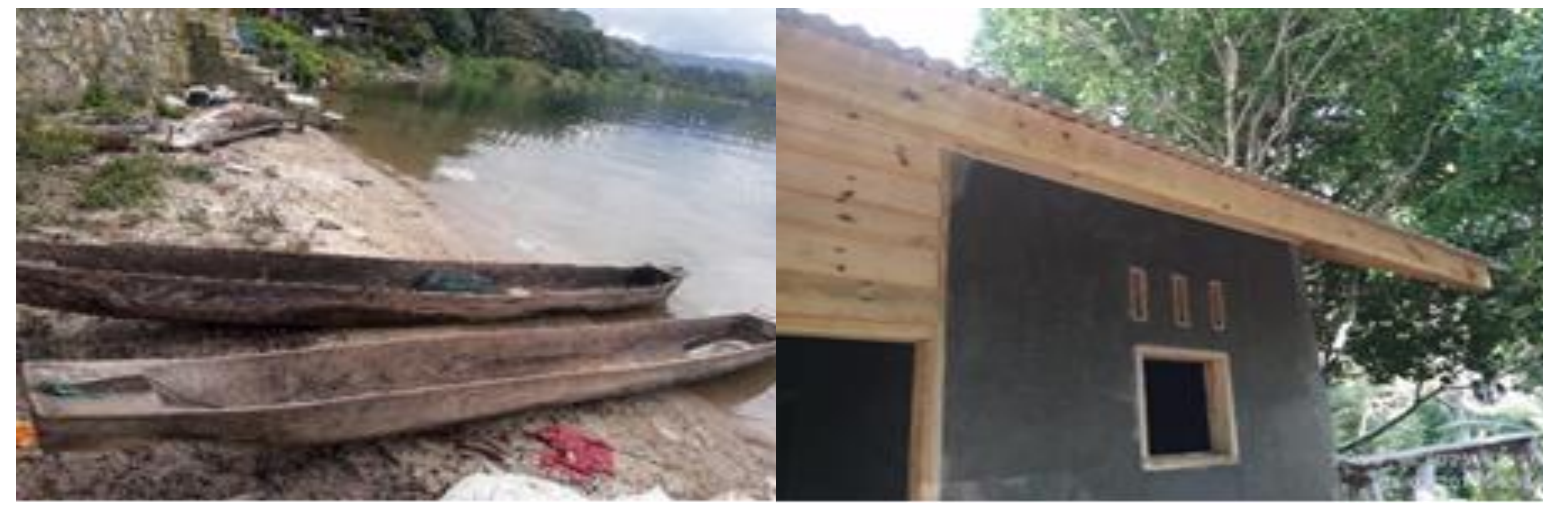

(a) (b)

Gambar (Figure) 2. (a) Masyarakat desa memanfaatkan kayu suren menjadi (a) perahu, dan

(b) bahan bangunan. (Villagers used trunk of suren (a) for boats, and (b) for building materials) 


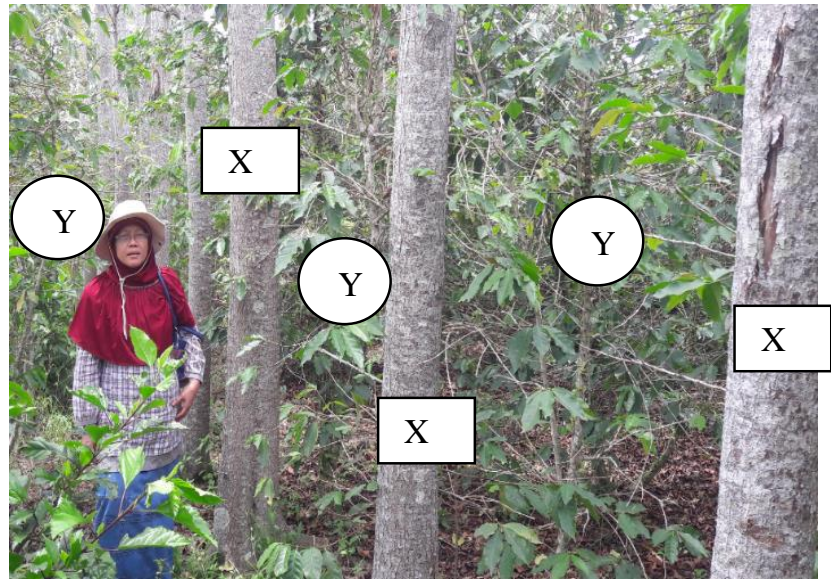

(a)

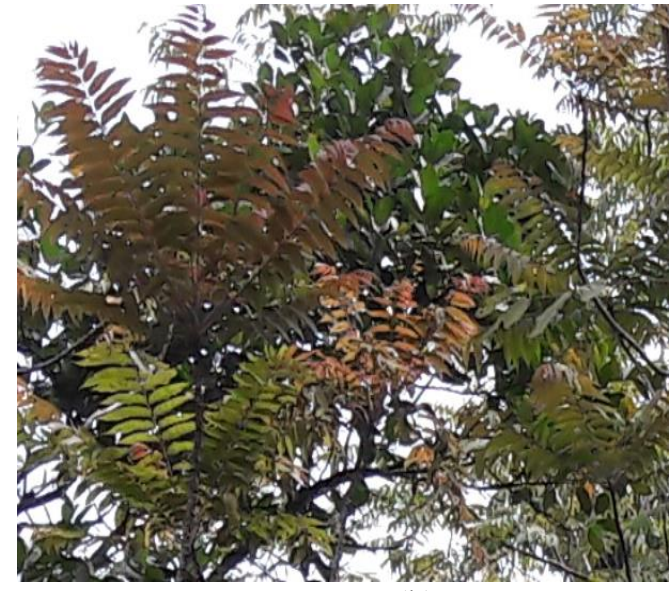

(b)

Gambar (Figure) 3. Pemanfaatan suren sebagai pembatas lahan dan naungan (The use of suren for land boundaries and shade (a)), dan daun suren untuk makanan lalapan, obat-obatan dan insektisida alami (suren leaf for fresh food, medicines and natural insecticides $(b)$ )

Tabel (Table) 4. Sistem Agroforestri di Desa Sipolha (Agroforestry System at Sipolha Village)

\begin{tabular}{|c|c|c|c|c|}
\hline $\begin{array}{c}\text { Tanaman } \\
\text { pokok (Staple } \\
\text { crops) }\end{array}$ & $\begin{array}{l}\text { Tanaman sela } \\
\text { (Intercropping) }\end{array}$ & $\begin{array}{c}\text { Permudaan } \\
\text { (Regeneration) }\end{array}$ & $\begin{array}{c}\text { Jarak } \\
\text { tanam } \\
\text { (Spacing) }\end{array}$ & $\begin{array}{l}\text { Kondisi tegakan } \\
\text { (Tree condition) }\end{array}$ \\
\hline \multirow[t]{3}{*}{ Suren } & $\begin{array}{l}\text { Kopi (Coffe) } \\
\text { Alpukat (Alvocado) } \\
\text { Mangga (Mango) }\end{array}$ & $\begin{array}{l}\text { Bibit, anakan, biji } \\
\text { (Seeds, saplings, } \\
\text { seedlings) }\end{array}$ & $5 \mathrm{~m} \times 6 \mathrm{~m}$ & $\begin{array}{l}\text { Baik (Good) } \\
\text { Baik (Good) }\end{array}$ \\
\hline & Kemiri (Candlenut) & & & \\
\hline & $\begin{array}{l}\text { Cabe, jahe jagung } \\
\text { (Chili, corn, ginger) }\end{array}$ & $\begin{array}{l}\text { Bibit, rhizoma, } \\
\text { benih (seeds, } \\
\text { rhizomes, saplings) }\end{array}$ & - & \\
\hline
\end{tabular}

Sumber (Sources) : Sima (2019)

Kajian kelayakan ekonomi budi daya tanaman suren dengan pola tanam agroforestri oleh masyarakat di Desa Sipolha Horison dilakukan dengan menggunakan kriteria kelayakan Net Present Value (NPV), yaitu nilai saat ini yang mencerminkan nilai keuntungan yang diperoleh selama jangka waktu pengusahaan dengan memperhitungkan nilai waktu dari uang atau time value of money. Komponen biaya di lokasi penelitian terdiri dari pengadaan alat pertanian (beko, parang, cangkul, pulper, hand sprayer dan gembor), biaya pengadaan bibit, pestisida, herbisida, pupuk, tenaga kerja serta biaya operasional, meliputi biaya pemeliharaan alat pertanian dan biaya pajak lahan. Sumber pendapatan berasal dari tanaman suren dan jenis pohon serbaguna (JPSG).

\section{B. Pembahasan}

\section{Karakteristik masyarakat desa sekitar hutan}

Faktor umur sangat terkait hubungannya dengan kemampuan dan pengalaman dalam melakukan kegiatan juga sangat mempengaruhi kemampuan kerja baik secara fisik maupun mental. Petani yang berumur relatif muda mempunyai kemampuan fisik yang kuat serta semangat kerja lebih tinggi dibandingkan petani yang berumur lebih 
tua. Secara keseluruhan semua respronden berada pada ketegori umur produktif. Menurut Aryana (2016) dan Kembar, Budhi, \& Yuliarmi (2016), masyarakat usia produktif mempunyai produktivitas lebih besar bila dibandingkan dengan mereka yang berada pada usia tidak produktif.

Kemampuan dan keterampilan petani dalam menerima inovasi dan penyerapan informasi yang berkaitan dengan usahanya berkorelasi positif dengan tingkat pendidikan responden (Juariyah, 2010). Semakin tinggi tingkat pendidikan petani, maka akan semakin bertambah kemampuan dan keterampilan petani terhadap inovasi baru. Petani yang berpendidikan tinggi akan lebih mudah menerima, menerapkan dan bahkan mengembangkan suatu teknologi baru yang berguna (Rismayadi, 2015).

Luas lahan berpengaruh terhadap tingkat pendapatan petani karena luas lahan yang dimiliki petani menentukan besar kecilnya produksi yang dihasilkan. Lahan yang dimiliki oleh responden petani agroforestri suren bervariasi, yaitu 0,24 1,45 ha, namun mayoritas petani memiliki lahan garapan antara 0,24-0,52 ha, yaitu sebanyak 23 responden. Hal ini sesuai dengan rata-rata luas lahan garapan petani di Indonesia, yaitu 0,48 (Nazam, Sabiham, Pramudya, Widiatmaka, \& Rusastra, 2011). Luas lahan standar yang harus dimiliki petani untuk Pulau Jawa minimal 0,25 ha, sedangkan untuk luar Pulau Jawa minimal 0,5 ha (Mulyani, 2017). Semakin besar luas lahan yang dimiliki dan dikelola dengan baik, maka hasil yang diperoleh juga akan semakin besar. Sebaliknya, luas lahan yang sempit cenderung menghasilkan lebih sedikit. Lahan sebagai media tumbuh tanaman merupakan faktor produksi yang mempengaruhi usaha tani.

\section{Pemanfaatan suren}

Hutan penting bagi kehidupan masyarakat lokal di sebagian besar negara berkembang. Masyarakat lokal bergantung pada sumber daya hutan untuk berbagai produk seperti kayu bakar, bahan bangunan, obat-obatan, dan makanan (Pandey et al.,
2016; Latifah, 2020). Masyarakat Desa Sipolha Horison memanfaatkan tanaman suren pada setiap bagian dari pohon suren, yaitu batang, daun dan buahnya. Ketika tanaman suren masih muda di bawah tegakan ditanami tanaman tumpang sari, seperti cabe, jahe dan jagung (Tabel 4). Tetapi pada saat tanaman suren sudah besar, di bawah tegakan tidak bisa ditanami lagi karena tanaman tumpang sari tidak dapat tumbuh optimal di bawah naungan (Imru, Wogderess, \& Gidada, 2015; Latifah et al., 2019).

Masyarakat desa memanfaatkan daun suren yang akan dikonsumsi dengan merendam air panas sebelum dimakan ataupun dapat dikonsumsi secara langsung, yang sebelumnya dibersihkan dengan air biasa. Daun suren juga dimanfaatkan untuk insektisida alami dengan cara menyemprotan ekstrak daun suren ke tanaman yang berhama. Menurut Harneti, Desi, Nurlelasari (2018), ekstrak daun dan biji tanaman suren dapat digunakan sebagai insektisida alami. Suren merupakan salah satu jenis tanaman yang mempunyai peluang untuk digunakan sebagai insektisida alami, karena keberadaannya cukup melimpah dan mengandung senyawa aktif yang dapat berfungsi sebagai penolak, penarik, antifertilitas (pemandul), dan pembunuh hama (Harneti et al., 2018). Pemanfaatan daun suren sebagai salah satu hasil hutan non kayu dapat menjadi sumber mata pencaharian sampingan masyarakat di sekitar hutan (Latifah, \& Lubis, 2020).

Masyarakat lebih banyak memanfaatkan suren pada bagian batang sedangkan yang paling sedikit dimanfaatkan masyarakat adalah bagian daun suren. Kulit batang dan buah suren dapat disuling menjadi minyak esensial, namun masyarakat di Desa Sipolha Horison masih minim pengetahuan tentang metode pengolahannya.

Masyarakat setempat turun temurun secara umum memakai hasil kayu dari pohon suren untuk diolah menjadi papan dan broti (kayu gergajian dengan tebal kayu lebih besar atau sama dengan 
tebalnya). Ada juga yang memanfaatkan kayu suren untuk membuat pintu, jendela, dinding rumah dan kusen pintu atau jendela untuk pembangunan rumah sendiri. Selain dimanfaatkan sebagai bahan baku pembuatan rumah, pohon suren juga sebagai bahan baku untuk pembuatan kapal dan perahu. Pohon suren dijual kepada pengusaha kapal sebagai bahan baku pembuatan kapal dan sampan. Salah satu responden pemilik usaha pembuatan kapal yang sekaligus juga perkerja dalam pembuatan kapal, menyampaikan alasan utama memilih kayu suren adalah karena sifatnya yang tahan terhadap air, tidak mudah membusuk dan lentur, sehingga mudah dibentuk.

Masyarakat melakukan perbanyakan suren dengan bibit yang tumbuh secara alami, sebagian dibeli di tempat pembibitan, dan mendapatkan bibit dari pemerintah yang dibagikan dalam program penghijauan kawasan Danau Toba. Penanaman pohon suren yang dilakukan oleh masyarakat di lahan sebagai naungan tanaman semusim, pemecah angin dan kebanyakan dibuat sebagai pembatas lahan (Gambar 2b). Tanaman suren ditanam petani sebagai tanaman penaung tanaman kopi untuk mendukung pertumbuhannya. Suren dapat memberikan intensitas cahaya matahari yang cukup pada tanaman kopi yang tumbuh dibawahnya, sehingga tanaman kopi dapat tumbuh dan berkembang dengan baik serta terjaga produktivitasnya. Pohon peneduh dapat melindungi tanaman kopi dari tekanan lingkungan yang merugikan dan dapat meningkatkan produksi kopi dibandingkan dengan tanaman kopi yang ditanam di bawah sinar matahari langsung (Imru, Wogderess, \& Gidada, 2015).

Pohon suren juga merupakan pohon yang banyak dimanfaatkan oleh penduduk Desa Sipolha Horison, karena teksturnya yang tidak mudah mengalami pembusukan atau dimakan rayap, menampilkan corak dekoratif unik, memiliki nilai kekuatan dan keawetan relatif tinggi dibandingkan jenis pohon lainnya seperti sengon (Pandit et al., 2011).

\section{Kelayakan ekonomi budi daya tanaman suren}

Bagi petani, pohon suren umumnya dianggap sebagai tabungan yang akan ditebang dan dijual saat ada kebutuhan mendadak, seperti hajatan dan biaya pendidikan. Petani akan menebang pohon sesuai dengan kebutuhan. Nilai ekonomi kayu suren juga cukup tinggi, sehingga dapat meningkatkan pendapatan petani bahkan dapat meningkatkan devisa negara (Latifah et al., 2018 dan Irawanti et al., 2012). Analisis nilai ekonomi tanaman suren dilakukan dengan menggunakan $\mathrm{Net}$ Present Value (NPV), yaitu nilai saat ini yang mencerminkan nilai keuntungan yang diperoleh selama jangka waktu pengusahaan dengan memperhitungkan nilai waktu dari uang atau time value of money.

Kriteria Net Present Value didasarkan pada konsep mendiskonto seluruh aliran kas ke nilai sekarang. Tingkat suku bunga yang dipakai berdasarkan tingkat suku buga pasar, yaitu $17,5 \%$. Tanaman suren yang dianalisis dalam penelitian ini adalah suren rakyat dengan berpedoman pada data penerimaan, pengeluaran (biaya) dan pendapatan bersih yang diperoleh per ha per daur dari masing-masing pola usaha tani suren dengan tanaman sela yang kemudian dilakukan analisis untuk mendapatkan nilai NPV. Nilai total NPV di Desa Sipolha Horison sebesar Rp 29.153.089 yang berarti besarnya nilai Net Present Value adalah positif atau NPV > 0 , yang berarti bahwa pola agroforestri suren tersebut layak secara finansial. Semakin tinggi nilai $\mathrm{Net}$ Present Value, maka usaha tersebut semakin baik dan usaha agroforestri suren tersebut semakin menguntungkan. Nilai NPV terbesar diperoleh dari kombinasi tanaman suren dengan kopi dan kemiri, sedangkan nilai NPV terkecil diperoleh dari kombinasi tanaman suren dengan mangga dan alpukat.

Nilai NPV di Desa Sipolha Horison, menunjukkan bahwa usaha hutan rakyat suren di Desa Sipolha Horison ini cukup mampu untuk membayar tingkat bunga 
yang lebih tinggi dari suku bunga yang berlaku yaitu $17,5 \%$. Perbandingan nilai NPV di Desa Mekar Sari Kabupaten Simalungun sebesar Rp 2.670.306.906/ kawasan/15 tahun (Latifah et al., 2018) dan di Desa Sibaganding, Kabupaten Simalungun sebesar Rp 166.792.216/ UT/daur. Bervariasinya nilai NPV pada beberapa desa di Kabupaten Simalungun dikarenakan adanya perbedaan pola-pola pengusahaan tanaman suren dengan jenis pohon serbaguna (JPSG), karakteristik responden, luas lahan, tingkat suku bunga yang berlaku dan komponen biaya yang dikeluarkan oleh petani.

Penanaman suren yang dilakukan masyarakat Desa Sipolha Horison sangatlah menguntungkan dan layak dijadikan sumber pendapatan atau tabungan untuk kebutuhan keluarga mereka. Usaha tanaman suren yang dilakukan oleh masyarakat Desa Sipolha Horison bukan merupakan satusatunya sumber pendapatan. Sumber pendapatan masyarakat lainnya berasal dari bekerja sebagai nelayan, bidan, dan pedagang, namun pendapatan terbesar berasal dari kegiatan usaha tani. Ditinjau dari kelayakan ekonomi, agroforestri suren sangat layak untuk dikembangkan oleh masyarakat di Desa Sipolha Horison. Keuntungan yang diperoleh petani cukup besar karena setiap lahan ditanami dengan tanaman suren dan berbagai jenis tanaman JPSG, sehingga memberikan hasil yang cukup besar serta dapat diperoleh secara kontinyu. Selain pertimbangan kelayakan ekonomi, dalam memilih komoditas unggulan, masyarakat juga harus mempertimbangkan kondisi lahan dan kemampuan masyarakat yang akan mengelola. Selain itu, untuk dapat lebih mengembangkan usahanya, masyarakat perlu mendapat dukungan/fasilitasi dari organisasi koperasi maupun kerja sama dengan mitra bisnis.

\section{KESIMPULAN DAN SARAN}

\section{A. Kesimpulan}

Masyarakat Desa Sipolha Horison, Kecamatan Sidamanik memanfaatkan beberapa bagian tanaman suren, seperti batang dan daun untuk berbagai keperluan seperti meubel, dinding rumah, kosen, bahan pembuatan perahu dan kapal, dan lalapan makan. Berdasarkan hasil kelayakan finansial dengan kriteria NPV, diperoleh nilai NPV sebesar Rp 29.153.089/ha/daur. Hal ini menunjukkan bahwa tanaman suren di Desa Sipolha Horison, Kecamatan Pematang Sidamanik, Kabupaten Simalungun layak untuk dibudidayakan dan dikembangkan.

\section{B. Saran}

Diperlukan penelitian lanjutan yang membandingkan tingkat pendapatan masyarakat dari masing masing pola penanaman suren, sehingga diketahui pola mana yang paling tinggi nilai ekonominya.

\section{UCAPAN TERIMA KASIH}

Terima kasih disampaikan kepada masyarakat Desa Sipolha Horison yang mendukung kami dalam melaksanakan penelitian. Kami juga mengucapkan terima kasih kepada Universitas Sumatera Utara yang telah memberikan ijin dan dukungan untuk melakukan penelitian.

\section{DAFTAR PUSTAKA}

Aji, G.B., Suryanto, J., Yulianti, R., Wirati, A., Abdurrahim, A.Y., \& Miranda, T.I. (2013). Pengembangan Model PHBM dan Hkm. Pusat Penelitian Kependudukan Lembaga Ilmu Pengetahuan Indonesia. Jakarta Selatan. https://doi.org/10.13140/RG.2.2.2810 8.72323

Asmaliyah. (2014). Potensi tanaman rimau (toona sinensis roem )untuk pengendalian hama di lapanganrimau. Ulasan (Toona sinensis Roem). 0711. 
Arikunto, S. (2006). Prosedur Penelitian Suatu Pendekatan Praktik.PT Rineka Cipta. Jakarta.

Dewi, I.N. (2018). Kemiskinan masyarakat sekitar hutan dan program perhutanan sosial. Info Teknis Eboni, 15(2), 65-77.

Lestari, F., \& Darwiati, W. (2014). Uji efikasi ekstrak daun dan biji dari tanaman suren, mimbadan sirsak terhadapmortalitas hama ulat gaharu. Jurnal Penelitian Hutan Tanaman 11(3), 165-171.

Harneti, Desi, \& Nurlelasari, M. (2018). Pemanfaatan Ekstrak Daun Suren. Universitas Padjadjaran.

Herawati, H., \& Santoso, H. (2011). Tropical forest susceptibility to and risk of fire under changing climate: A review of fire nature, policy and institutions in Indonesia. Forest Policy and Economics, 13(4), 227-233. https://doi.org/10.1016/j.forpol.2011.0 2.006.

Imru, N.O., Wogderess, M.D., \& Gidada, T.V. (2015). A study of the effects of shade on growth, production and quality of coffee (COFFEA ARABICA) in Ethiopia. International Journal of Agricultural Sciences, 5(5), 748-752.

Irawanti, S., Suka, A.P., \& Ekawati, S. (2012). Economic benefit and opportunity to develop community forestry of albizia in Pati District. Journal of Social and Economic Forestry Research, 9(3), 126-139.

Juariyah, S., \& Basrowi, S. (2010). Analisis kondisi sosial ekonomi dan tingkat pendidikan masyarakat Desa Srigading, Kecamatan Labuhan Maringgai, Kabupaten Lampung Timur. Jurnal Ekonomi \& Pendidikan, 7(1), 58-81.

Latifah, S., Afifuddin, Y., \& Widya, S. (2018). Analysis of community income on suren (Toona sureni (Blume) Merr.) and cacao crops (Theobroma cacao L.) in Simalungun, North Sumatera-Indonesia. IOP Conference Series: Earth and
Environmental Science, 122(1). https://doi.org/10.1088/17551315/122/1/012140.

Latifah, S., Purwoko, A., Hartini, K.S., Sadeli, A., \& Tambal, T.N.R. (2019). The practice of agroforestry Toona sureni merr by the community of Simalungun Regency, North Sumatera. IOP Conference Series: Earth and Environmental Science, 374(1), 6-11. https://doi.org/10.1088/17551315/374/1/012035.

Latifah, S., \& Lubis, N.A. (2020). Economic value of non timber forest products - A case study from South Tapanuli, North Sumatera, Indonesia. IOP Conference Series: Earth and Environmental Science, 454(1). https://doi.org/10.1088/17551315/454/1/012001

Muslich, M., \& Rulliaty, S. (2013). Uji Kuburan dan Uji di Laut. 31(4), 250257.

Nazam M., Sabiham, S., Pramudya, B., Widiatmaka, F.N., \& Rusastra, I.W. (2011). Penetapan luas lahan optimum usahatani padi sawah mendukung kemandirian pangan berkelanjutan di Nusa Tenggara Barat. Jurnal Agro ekonomi 29(2), 113-145.

Mulyani, A., \& Agus, F. (2017). Kebutuhan dan ketersediaan lahan cadangan untuk mewujudkan cita-cita Indonesia sebagai lumbung pangan dunia 2045. Jurnal Analisis Kebijakan Pertanian, 15(1), 1-17.

Pandey, A.K., Tripathi, Y.C., \& Kumar, A. (2016). Non timber forest products (NTFPs) for sustained livelihood: Challenges and strategies. Research Journal of Forestry, 10(1), 1-7. https://doi.org/10.3923/rjf.2016.1.7.

Pandit, I.K.N., Nandika, D., \& Darmawan, I.W. (2011). Analisis sifat dasar kayu hasil hutan tanaman rakyat. Jurnal Ilmu Pertanian Indonesia, 16(2), 119124.

Rismayadi, B. (2015). Faktor-faktor yang mempengaruhi produktivitas 
karyawan. Jurnal Manajemen \& Bisnis, 2(2), 187 -198.

Sima, H.M. (2019). Analisis Manfaat Ekonomi Tanaman Suren (Toona sureni) terhadap Masyarakat di Desa Sipolha, Kecamatan Pematang Sidamanik, Kabupaten Simalungun. [Skripsi]. Departemen Manajemen Hutan, Fakultas Kehutanan, Universitas Sumatera Utara. Medan

Suharti S, Ginoga, K.L, Murniati, Octavia, D., \& Windyoningrum, A. (2017). Langkah Strategis Menuju Percepatan Realisasi Capaian Program Perhutanan Sosial. Policy. 11(08), 18. 
Lampiran (Attachment) 1. Nilai NPV suren di Desa Sipolha Horison (NPV Value of suren in Sipolha Horison Village)

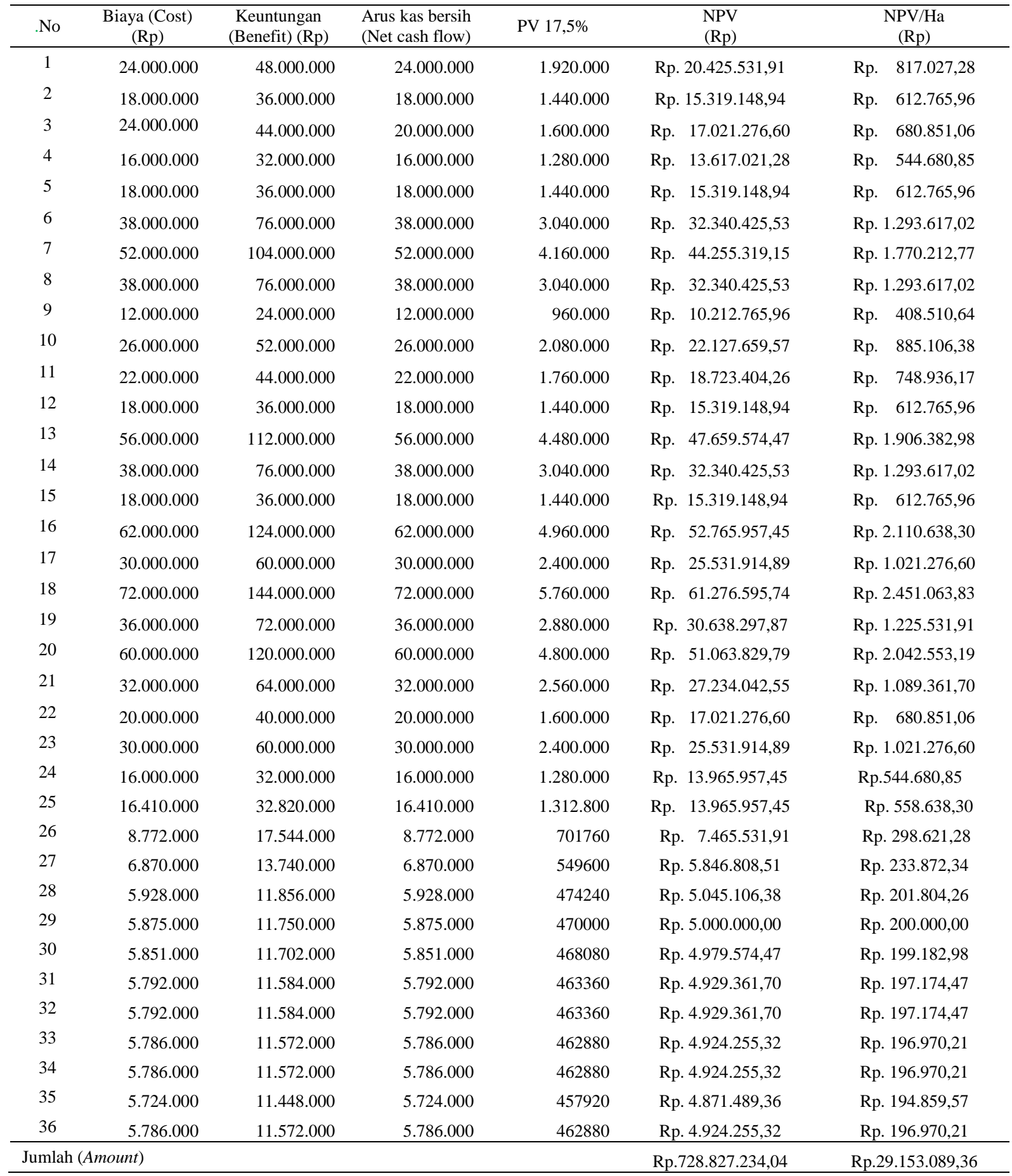


Jurnal Penelitian Hutan Tanaman

Vol 17 No. 2, Desember 2020, 87-99 